\title{
Discriminación y exclusión laboral en la comunidad LGBT: un estudio de caso en la localidad de chapinero, Bogotá Colombia
}

\author{
Jorge Jiménez-Castaño, Marleny Cardona-Acevedo y María \\ del Pilar Sánchez-Muñoz
}

\author{
Universidad de La Salle, Colombia, Universidad de Manizales, \\ Colombia, Universidad de La Salle, Colombia
}

Resumen

Los mercados de trabajo han estado acompañados de mecanismos que discriminan y segregan a ciertos grupos de la sociedad por su orientación sexual, sin importar las capacidades y potencialidades de los individuos. Este artículo presenta la caracterización de los perfiles empresariales y ocupacionales de un grupo de la comunidad LGBT en la localidad de Chapinero en BogotáColombia. La metodología empleada se basó en la implementación de entrevistas semiestructuradas, partiendo de un análisis descriptivo. Se encontró, en primer lugar, que la discriminación y segregación ocupacional varía para hombres homosexuales, mujeres lesbianas, personas bisexuales y transgeneristas, es decir, está en función de la identidad, construcción y manifestación corporal de la sexualidad; y en segundo lugar, las condiciones laborales de las personas entrevistadas afectan negativamente su calidad de vida.

Palabras clave: Discriminación Laboral, segregación ocupacional, mercado laboral, Comunidad LGBT.

\section{Abstract}

Discrimination and labor exclusion in the lgbt community: a case of study in chapinero district, Bogota Colombia

The labor markets has been partnered with discrimination and segregation mechanisms to specific groups of the society due to their sexual orientation, regardless the potential and characteristics of the human been. This article shows the business and occupational profiles characteristics for the LGBT community in Chapinero in Bogota-Colombia. The methodology used in this research is based on the implementation of semi-structured interviews starting from a descriptive analysis. It was found that in a first place, the discrimination and occupational segregation varies for homosexual men, lesbians, bisexual and transgender people. This means that, the segregation and discrimination are in function of the identity construction and body demonstration of the sexuality. In a second place, the working conditions of the surveyed people has a negative impact in their life quality.

Key words: Employment discrimination, occupational segregation, labor market, LGBT Community.

Agradecimientos: Este artículo es el resultado del trabajo de monografía "Perfiles ocupacionales de la comunidad LGBT en Chapinero", realizado por Jorge Jiménez Castaño para optar al título de Economista de la Universidad de La Salle. Este trabajo fue dirigido por Marleny Cardona Acevedo y contó con la colaboración de María del Pilar Sánchez Muñoz. 


\section{INTRODUCCIÓN}

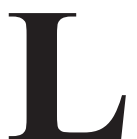

os mercados de trabajo han estado acompañados de mecanismos que discriminan y segregan a ciertos grupos de la sociedad sin importar las capacidades y potencialidades de los individuos. Estos fenómenos definen la ocupación y los perfiles laborales de las personas por sus diferencias y otras características.

Dentro de los mercados de trabajo algunos perfiles ocupacionales evidencian discriminación laboral, lo cual sucede cuando un grupo poblacional, que difiere de otras personas por procedencia étnica, sexo, por discapacidad, raza y orientación sexual, presenta tasas de desempleo mayores o está limitado a tener empleos de baja categoría y escasa remuneración; por consiguiente, se les dificulta alcanzar ciertos niveles jerárquicos en el sector formal, aunque estén calificados para ello y lógicamente sus salarios son bajos. Por su parte, la segregación ocupacional es la tendencia de que los individuos se empleen en diferentes ocupaciones por pertenecer a un grupo en específico (mujeres, indígenas, negros, etc.), separados unos de otros en la estructura ocupacional, lo cual significa la exclusión de estas personas por construcciones sociales (Baquero et al., 2000).

Con el paso del tiempo, las luchas contra la diferencia de religión, contra el racismo, esclavitud y los movimientos feministas de inicios del siglo $\mathrm{XX}$, han logrado disminuir la desigualdad de estos grupos frente al resto de la sociedad. Sin embargo, los fenómenos de discriminación y segregación laboral siguen latentes, especialmente en países en vía de desarrollo, donde algunos grupos poblacionales se encuentran en condiciones de vulnerabilidad por no ser reconocidos sus derechos, afectando directamente su vida laboral y calidad de vida, como es el caso de la comunidad LGBT. ${ }^{1}$

La discriminación y exclusión laboral por orientación sexual varía para hombres homosexuales, mujeres lesbianas, personas bisexuales y trans-

\footnotetext{
${ }^{1}$ De acuerdo con la Fundación Colombia Diversa, la sigla LGBT [...] “explica algunas definiciones relacionadas con la diversidad de orientación sexual y de expresión de género" [...] Se refiere a "Lesbianas (mujeres homosexuales: es decir, orientadas erótico-afectivamente hacia personas de su mismo sexo); Gays (hombres homosexuales); Bisexuales (personas orientadas eróticoafectivamente hacia ambos sexos) Trasgénero (persona que trascienden o rompen los esquemas convencionales de hombre y mujer, no solo en sus aspecto físico sino también en sus actitudes, maneras y gestos. El género hace referencia a la forma en que una persona se percibe a sí mismo en relación con las concepciones socioculturales de la masculinidad y feminidad. Los trangénero pueden iniciar o no cambios en su cuerpo); Transexuales (personas que han decidido mediante un proceso quirúrgico cambiar sus órganos sexuales externos), Travestis (parte del grupo transgénero, que se sienten y se visten de tiempo completo siguiendo los modelos establecidos para el género opuesto, Transformistas e intersexuales); Transformistas (travestis ocasionales, para presentaciones o espectáculos)" (Citado por Duque, 2008: 181).
} 
generistas, es decir, está en función de la identidad, construcción y manifestación corporal de la sexualidad. En los vínculos laborales, esta situación se presenta como un problema social contemporáneo, que nace por la falta de aceptación de la diversidad sexual y se contrapone con los patrones culturales patriarcales y homofóbicos.

En este sentido, los procesos de discriminación contra la población LGBT ocasionan que las relaciones sociales de dicha comunidad se establezcan dentro de parámetros de desigualdad, incluso en los mercados laborales, afectando la calidad de vida de los mismos, lo cual desemboca en el no reconocimiento como sujetos laborales y diversos a dicha población.

Estudios y análisis económicos previos han comprobado la existencia de segregación y discriminación laboral por sexo (hombre-mujer); sin embargo, estos trabajos no enfocan su análisis en el caso específico de la población LGBT o diversidad de género. En este sentido, esta investigación busca responder ¿cuáles son los perfiles ocupacionales de la comunidad LGBT en la Localidad de Chapinero teniendo en cuenta los actuales mercados de trabajo y la vulnerabilidad en la calidad de vida?

Para dar respuesta a la pregunta de investigación se realizó un análisis descriptivo del mercado laboral LGBT, utilizando una metodología basada en la implementación de entrevistas semiestructuradas, obteniendo información directa y detallada mediante una serie de preguntas cerradas y abiertas, las cuales brindan una aproximación de la realidad.

Dada la carencia de datos, las limitaciones y dificultad del trabajo de campo para la aplicación de las entrevistas, el desarrollo de la caracterización y descripción de los perfiles empresariales y ocupacionales LGBT se presenta como un estudio de caso $^{2}$ para seis establecimientos (demanda laboral) y 24 trabajadores que pertenecen a dicha comunidad (oferta laboral).

El presente documento inicialmente parte de algunas consideraciones teóricas para comprender la dinámica del mercado laboral frente a la diversidad sexual, haciendo referencia al modelo del gusto por la discriminación como explicación de la segregación laboral por sexo, la presentación de

\footnotetext{
${ }^{2}$ El estudio de caso como método de investigación en las ciencias sociales, utiliza la experiencia para la transmisión de conocimiento de la realidad a partir de la articulación de la teoría y los trabajos de campo. Con los estudios de caso se pretende aportar al conocimiento científico y realizar inferencias válidas por medio del estudio detallado de acontecimientos que se desarrollan en el contexto de la vida social. En este sentido, Yin (1994) define el estudio de caso como "una investigación empírica que estudia un fenómeno contemporáneo dentro de su contexto de la vida real, especialmente cuando los límites entre el fenómeno y su contexto no son claramente evidentes. [...] Una investigación de estudio de caso trata exitosamente con una situación técnicamente distintiva en la cual hay muchas más variables de interés que datos observacionales; y, como resultado, se basa en múltiples fuentes de evidencia, con datos que deben converger en un estilo de triangulación; y, también como resultado, se beneficia del desarrollo previo de proposiciones teóricas que guían la recolección y el análisis de datos" (Citado por Yacuzzi, 2005: 3).
} 
teorías de segmentación laboral, calidad de vida, de trabajo y reflexiones sobre injusticia socioeconómica de algunos sectores de la sociedad. La segunda parte presenta una breve descripción de los lineamientos normativos a nivel distrital y local en pro de la protección y garantía de los derechos de la población LGBT.

La tercera parte muestra la descripción geográfica, político-administrativa de la localidad de Chapinero, y el perfil económico y empresarial LGBT en esta zona. La cuarta, presenta el estudio de caso del mercado laboral de la comunidad, representado por el análisis de la oferta y demanda laboral de la población. La quinta parte describe las condiciones, exigencias y calidad laboral de las personas entrevistadas, para determinar el bienestar y calidad de vida de las mismas. En la sexta y última parte se presentan las conclusiones y algunas recomendaciones.

\section{Aproximación teórica PARA la COMPRENSIÓn DEL MERCADo}

\section{LABORAL EN EL CONTEXTO DE LA DIVERSIDAD SEXUAL}

\section{Modelo del gusto por la discriminación como explicación de la segregación laboral por sexo}

La literatura para el análisis de la discriminación laboral por sexo reconoce la influencia y comportamiento en los mercados laborales frente a la diversidad sexual. Siguiendo a Larrañaga (2000: 11), desde el punto de vista neoclásico, Becker (1985) formuló el "modelo del gusto por la discriminación", el cual se entiende como una preferencia que el empresario discriminador está dispuesto a asumir, en este caso con la población LGBT. En otras palabras, el gusto por la discriminación de los empresarios se explica por la disposición del empleador de renunciar a la eficiencia económica, a la maximización de producción y de beneficios para ejercer sus prejuicios frente a un grupo en específico de la sociedad.

Dado que el empresario varón no tiene prejuicios para contratar hombres, el coste de contratar a uno es el salario (Wh). Sin embargo, para los empresarios que ejercen discriminación, el coste de contratar una mujer es el salario de este trabajador (Wm), más el valor monetario del coste psíquico, el cual está determinado por un coeficiente de discriminación (d), es decir, $(\mathrm{Wm}+\mathrm{d})$. Por tanto, el empresario responde a las condiciones del mercado laboral regulado por el salario, donde contratará mujeres si su salario es inferior al de los hombres.

Lo anterior hace referencia al ejercicio de discriminación por parte de los empleadores, pero el modelo del gusto por la discriminación indica que 
ésta no solo proviene de este grupo, sino también de otros grupos dentro de los mercados laborales y en las mismas empresas.

En este sentido, siguiendo el trabajo de Higua (2012), los gustos de la discriminación también surgen de los empleados y de los consumidores. La discriminación por parte de los empleados hace alusión a la presencia de grupos mayoritarios, quienes también tienen prejuicios contra un grupo minoritario, es por tal motivo que no gustan de laborar con estos. Este tipo de discriminación ocasiona el desplazamiento del grupo minoritario a oficios en donde la presencia del grupo mayoritario es nula y su efecto es la reproducción de la segregación laboral.

\section{Teorías de segmentación y de mercados de trabajo internos}

La situación laboral a la que se enfrentan la población LGBT podría ser sustentada y comprendida bajo la teoría de segmentación del mercado de trabajo y de los mercados internos. A partir de estas teorías y su articulación con los resultados del trabajo de campo de esta investigación, se puede describir la concentración de la comunidad de estudio en los sectores formales o informales de los mercados laborales de Chapinero y determinar la segregación laboral que enfrentan.

En primer lugar, Piore (1969) se enfoca en la hipótesis del mercado dual del trabajo, partiendo de la teoría de segmentación del mercado laboral, el cual está dividido en dos sectores, el primario y el secundario. El primero, también llamado sector formal, brinda puestos de trabajo con salarios altos, buenas condiciones laborales, posibilidades de ascenso y estabilidad en el empleo. Dentro del sector primario, es necesario distinguir un segmento superior específico de los empleos profesionales muy cualificados y un segmento inferior característico de los empleos de cualificación media. Por otro lado, los puestos del sector secundario o sector informal, tienden a ofrecer salarios bajos, tener peores condiciones de trabajo, inestabilidad en el empleo y contratos temporales (Citado por Larrañaga, 2000: 16).

En segundo lugar, Doeringer y Piore (1970) explicaron la dinámica del sector primario del mercado laboral anteriormente nombrado. Para ello, se basaron en la teoría de mercados de trabajo internos que:

Se fundamenta en la idea de que pueden existir normas y hábitos dentro de las empresas que determinen su trabajo, organización, modelos de selección de personal o estructuras de remuneración. [...] En general, en un mercado interno de trabajo, el empleo y el salario no se determinan, por el libre juego de las fuerzas del mercado, sino por normas y procedimientos administrativos internos (citado por Carrasco et al., 2011: 97). 


\section{Trabajo digno y calidad de vida: enfoque de capacidades}

Conseguir una distribución económica efectiva para la sociedad, basada en la justicia social y de género, en el reconocimiento de los derechos, bienestar de la población y en el funcionamiento pleno de las potencialidades y libertades de cada individuo, es una labor que se debe dar prioridad. En este sentido, comprender la dinámica de la discriminación social contra la comunidad LGBT y sus efectos en espacios laborales, implica reconocer e incluir, en el estudio económico, particularidades culturales, morales y políticas.

Actualmente, la pobreza y desigualdad son fenómenos que agobian a ciertos grupos poblaciones, especialmente en países en vía de desarrollo, donde gran cantidad de personas no tienen la oportunidad de satisfacer sus necesidades básicas y la vida se convierte en una lucha por sobrevivir en un ambiente de injusticia social.

Es común que el interés por medir el bienestar humano sea considerado como una combinación de elementos objetivos como el PIB per cápita, el ingreso o renta y su evaluación individual. Pero existen varios autores que se refieren a la calidad de vida, no como una medida compuesta por estos elementos, sino también por factores subjetivos, incluyendo aspectos como el bienestar emocional, salud, trabajo y otras formas de actividad productiva, relaciones sociales y seguridad, que determinan la construcción del desarrollo económico desde una perspectiva cultural y humana (Ardila, 2003).

Dentro de este grupo de pensadores se destacan Sen (1996) y Nussbaum (2002) y (2005), quienes tienen como objetivo medir la calidad de vida a partir de la perspectiva de capacidades. En palabras de Sen (1996: 55-56), las capacidades "representan partes del estado de una persona: en particular, las cosas que logra hacer o ser al vivir", las cuales debería tener toda persona para poder realizarse humanamente, en igualdad de condiciones que los demás.

En este sentido, Sen (1996) indica que el desarrollo de una sociedad depende principalmente de la posibilidad efectiva de realizarse plenamente, más no del aumento en el ingreso económico o el desarrollo en función de utilidad, puesto que estas variables, en primer lugar, invisibilizan el fenómeno de desigualdad en la distribución económica y, en segundo lugar, resultan inadecuados porque no tienen en cuenta la heterogeneidad de los aspectos del desarrollo.

Además de que las capacidades "constituyen un criterio por excelencia para el reconocimiento de derechos a las personas" (Sen citado en Nuss- 
baum, 2005: 8), también brindan la forma más conveniente y satisfactoria, en términos éticos, para abordar la igualdad como objetivo político y no como una igualdad de utilidad o bienestar. ${ }^{3}$ Igualmente, las capacidades incluyen varias de las titulaciones destacadas por el movimiento de los derechos humanos, ya que intervienen no solo en la generación de libertades políticas y civiles, sino también en el reconocimiento y protección de derechos económicos y sociales (Sen citado en Nussbaum, 2005).

Bajo una postura comunitarista Nussbaum propone una lista de 10 capacidades humanas básicas, que suministran las razones para exigir el reconocimiento moral, político o jurídico de un derecho. Este enfoque de capacidades se apropia de la concepción de la dignidad del hombre y de la vida, apropiándose de consideraciones pluralistas, con una visión hacia la diferencia cultural.

Con los objetivos de medir y comparar los índices de calidad de vida entre sociedades y la formulación de principios políticos básicos que juegan un papel importante en las garantías constitucionales fundamentales, Nussbaum (2007) propone las siguientes capacidades básicas humanas fundamentales: "Vida, Salud física, Integridad física, Sentidos, Imaginación y pensamiento, Emociones, Razón práctica, Afiliación, Otras especies, Juego, Control sobre el propio entorno" (Nussbaum, 2007: 88-89).

Nussbaum determina que "una sociedad que no garantice tales capacidades a todos sus ciudadanos en un umbral adecuado, no alcanza a ser una sociedad completamente justa, con independencia de su nivel de opulencia" (2005: 31).

\section{Una visión sociológica y filosófica de la discriminación hacia la población LGBT}

Fraser (1997) indica que la comunidad LGBT sufre un problema basado en el no reconocimiento como sujetos sociales, marcado por un entorno de injusticia fundamental y conflicto que implica la lucha por el reconocimiento de esta población. En este sentido Fraser propone dos concepciones amplias de la injusticia que sufre la comunidad, la injusticia socioeconómica y la injusticia cultural o simbólica. En palabras de la autora, la primera

[...] está arraigada en la estructura político-económica de la sociedad. Los ejemplos de este tipo de injusticia incluyen la explotación [...]; la marginación económica [...]; y la privación de los bienes materiales indispensables para llevar una vida digna (Fraser, 1997: 21).

\footnotetext{
${ }^{3}$ Desde la perspectiva de Sen, la igualdad se concibe como el objetivo central para las sociedades que tienen como fin la promoción de la justicia social.
} 
Sobre la injusticia cultural o simbólica Fraser afirma que “[...] Está arraigada en los patrones sociales de representación, interpretación y comunicación. Los ejemplos de este tipo de injusticia incluyen la dominación cultural [...]; el no reconocimiento [...]; y el irrespeto" (Fraser, 1997: 22).

De igual manera, Bourdieu (2000; citado por Duque, 2008) hace referencia al tipo de injusticia contra el sector LGBT como fenómeno que incluye dominación cultural, debido a que esta comunidad debe ceñirse a los patrones androcentristas, heterosexistas y homofóbicos ${ }^{4}$ de la sociedad, fortaleciendo aún más la marginación de dicha población, su segmentación y segregación, en especial en los mercados de trabajo (Pérez et al., 2013). Es por ello que este autor conceptualiza la dominación simbólica basado en la negación, la exclusión social y la invisibilización del sector LGBTI como:

La forma especial de dominación simbólica que sufren los homosexuales, afectados por un estigma que, a diferencia del color de la piel o la feminidad, puede estar oculto (o exhibido) se impone a través de los actos colectivos de categorización que hace que existan unas diferencias significativas, negativamente marcadas, y a partir de unos grupos, unas categorías sociales estigmatizadas (Bourdieu, 2000; citado por Duque, 2008: 183).

\section{CONTEXTO NORMATIVO}

A nivel distrital (Bogotá) y local (Chapinero), en pro de la protección y garantía plena de los derechos de la comunidad LGBT, se ha desarrollado un lineamiento de políticas públicas orientado a la diversidad sexual para garantizar el libre ejercicio de las capacidades, promover el reconocimiento, bienestar y mejoramiento de la calidad de vida de ésta población.

En primer lugar, bajo la administración de Luis Eduardo Garzón (20042008), ${ }^{5}$ se constituye el Decreto 608 del 28 de Diciembre de 2007, el cual tiene como objetivo generar capacidades y desarrollos institucionales para una efectiva representación de los intereses de la población LGBT en los espacios de decisión de la ciudad y promover una cultura ciudadana basada en el derecho a una vida libre de violencias y de discriminación por iden-

\footnotetext{
${ }^{4} \mathrm{El}$ androcentrismo "es el patrón institucionalizado de valor cultural que privilegia los rasgos asociados con el hombre y lo masculino al tiempo que devalúa lo codificado con la mujer y lo femenino"; el heterosexismo "es la construcción autoritaria de normas culturales que privilegian y promueven la heterosexualidad" y la homofobia "es la devaluación cultural de la homosexualidad que lleva al desprecio de las personas LGBT" (Duque, 2008: 192).

${ }^{5}$ A partir de su administración se diseñan los lineamientos de las políticas públicas para visibilizar las necesidades de protección, promoción, garantía y restitución de los derechos de la comunidad LGBT en Bogotá.
} 
tidad de género u orientación sexual (Alcaldía Mayor de Bogotá, 2008c: $8,58-59)$.

En segundo lugar, en la administración de Samuel Moreno Rojas (20082012), se estableció el programa "Bogotá respeta la diversidad", el cual apuesta por el impulso de acciones para desnaturalizar la discriminación, potenciar las capacidades de los grupos vulnerables, reconocer las particularidades por orientación sexual y ampliar el ejercicio de las capacidades humanas (Alcaldía Mayor de Bogotá, 2008c: 22).

Por último, durante el mandato de Gustavo Petro, mediante el Decreto 062 de 2014, se adopta la estrategia "Ambientes laborales inclusivos", el cual se desarrolla mediante el diseño y aplicación de instrumentos que permitan identificar formas de discriminación desde y hacia servidores públicos; el desarrollo en entidades de estrategias que reduzcan los mecanismos de discriminación y; el desarrollo de procesos, procedimientos y manuales para garantizar a toda la población LGBT sus derechos (Alcaldía Mayor de Bogotá, 2014: 5).

A nivel local las acciones para el reconocimiento de la comunidad LGBT en Chapinero son originados a partir de los planes de desarrollo distritales. Por lo tanto, la localidad de Chapinero también empieza a reestructurar sus políticas a partir de la publicación del Decreto 608 de 2007 anteriormente nombrado, entendido como una apuesta de la administración de Luis Eduardo Garzón para la generación de políticas públicas LGBT. Es por esto, que la Alcaldía Local de Chapinero ha tenido que articular los planes de desarrollo y políticas públicas para brindar un espacio urbano adecuado para el desarrollo de tendencias de diversidad sexual y el reconocimiento de los derechos de la población LGBT.

Bajo la perspectiva de una construcción de "Ciudad de Derechos", el plan de desarrollo local de Banca Inés Durán Hernández (2009-2012), ${ }^{6}$ gestionó el programa "Bogotá respeta la diversidad" enmarcado por el proyecto "Bogotá diversa", el cual estableció como meta la y asistencia a personas LGBT en centros comunitarios a través de la implementación de acciones incluidas en la política pública para dicha comunidad (Junta Administradora Local de Chapinero, 2008: 24).

Posteriormente, la administración de Mauricio Jaramillo Cabrera (2013-2016), adelantó varios programas, entre los cuales se encuentra: i) la sensibilización de cuatro mil personas de la comunidad educativa para prevenir la discriminación; ii) la realización de actividades culturales para la

${ }^{6}$ Reconocida ingeniera industrial de la Universidad de Los Andes y activista LGBT, integrante del Polo de Rosa y quien en el momento de asumir el cargo de mandataria local reconoció abiertamente su homosexualidad (Rodríguez, 2012: 60). 
visibilización y reconocimiento de los derechos LGBT y iii) la vinculación de 3200 personas para prevenir la violencia contra la mujer y comunidad LGBT (Junta Administradora Local de Chapinero, 2012).

Las anteriores acciones han hecho que la participación de la ciudadanía LGBT en Chapinero aumente de forma considerable. Siguiendo a Rodríguez (2012), algunas de las iniciativas de la comunidad LGBT, para hacer parte de las decisiones y gestión pública de la localidad, se han gestado en el Consejo de Planeación Local (CPL), en el Comité Local de Mujer y Género (CLMyG), en el Consejo Local de Juventud (CLJ) y en las Juntas Zonales de Seguridad (JZS).

Las iniciativas y participación de la población LGBT ha fortalecido el proceso de visibilización de este grupo por medio de la territorialización de la localidad y ha logrado que la imagen de Chapinero como distrito LGBT no sea determinada únicamente por bares, discotecas, restaurantes y saunas, sino también por la presencia de instituciones y organizaciones no gubernamentales que trabajan por la protección de dicha población.

Como ejemplo de lo anterior, se puede referenciar la creación de la Cámara de Comercio LGBT Colombia (CCLGBTCo) en Septiembre de $2012,{ }^{7}$ la cual tiene como objetivo promover el reconocimiento profesional y estimular la creación de negocios para esta población.

\section{LOCALIDAD DE CHAPINERO: CARACTERÍSTICAS GEOGRÁFICAS Y DIVISIÓN POLÍTICO-ADMINISTRATIVA}

La localidad de Chapinero se encuentra ubicada al centro-oriente de Bogotá, tiene una extensión total de 3898.96 hectáreas (Alcaldía Mayor de Bogotá, 2004). Está conformada por cinco Unidades de Planeación Zonal (UPZ) $^{8}$ : UPZ 88 El Refugio, UPZ 89 San Isidro-Patios, UPZ 90 Pardo Rubio, UPZ 97 Chicó Lago y UPZ 99 Chapinero.

En los últimos años la UPZ 99 de Chapinero se ha caracterizado por ser un territorio LGBT. La apropiación del espacio por parte de ésta comunidad se debe a la necesidad de satisfacer sus demandas, convivir y desarrollarse de manera libre, buscar el reconocimiento de la diversidad sexual y sus

${ }^{7}$ Colombia es el tercer país de América en tener Cámara de Comercio LGBT después de Estados Unidos con la National Gay \& Lesbian Chamber of Commerce (NGLCC) y Argentina con la Cámara de Comercio LGBT Argentina, fundada por Gustavo Noguera y Pablo De Lucca (EL UNIVERSAL, 2012).

${ }^{8}$ Las UPZ funcionan como "instrumento de planeación, a escala zonal y vecinal, que condiciona las políticas generales del Plan de Ordenamiento Territorial (POT) con respecto a las condiciones específicas de un conjunto de barrios". En otras palabras, son "territorios conformados por un conjunto de barrios que mantienen una unidad morfológica o funcional y que se localizan en las zonas de suelo urbano y suelo de expansión" (Alcaldía Mayor de Bogotá, 2004: 15). 
derechos frente a los demás grupos de la sociedad, lo cual ha ocasionado que esta población desarrolle tendencias de vida, actividades económicas, de ocio y entretenimiento. Lo anterior se articula con el diseño y aplicación de lineamientos de politicas por parte de la Alcaldía Mayor de Bogotá y la Alcaldía Local de Chapinero con el fin de visibilizar, reconocer y mejorar la calidad de vida de la población.

Las nuevas tendencias de vida, diferentes comportamientos y manifestaciones culturales, la promocion de la igualdad y el reconocimiento de la diversidad sexual gestado a partir del diseño de lineamientos de politicas públicas impulsó la configuración de la UPZ 99 Chapinero como distrito LGBT, la cual tiene una extensión de 161.26 hectáreas, que representan 13.06 por ciento del área total de la localidad (Alcaldía Mayor de Bogotá, 2008c).

\section{Actividades económicas de la comunidad LGBT en la UPZ 99 de Chapinero}

El asentamiento de la comunidad LGBT en en la UPZ 99 Chapinero ha logrado un cambio drástico en la percepción de la ciudad y el uso del suelo urbano. El deseo de satisfaser las necesidades de la comunidad se ve reflejado en la presencia de economías diversas y de espacios donde no exista discriminación ni prejuicios laborales por orientación sexual.

Las unidades productivas propias de la comunidad LGBT se caracterizan por ser en su mayoria de tipo comercial, representadas por sex shop, bares y discotecas, cafés, videos, cabinas de internet gay, saunas, moteles y residencias. Estos establecimientos se caracterizan por contribuir al libre desarrollo tanto de la personalidad como de la sexualidad de la comunidad. Este sector cuenta "con 39 bares y discotecas, 31 cafés y restaurantes, cinco saunas, 22 videos, 7 establecimientos de ropa y accesorios y siete hoteles y hospedajes" (Luna, 2011: 8).

\section{ESTUdio de CASO del MERCADo laboral de la POBLACión LGBT}

\section{Análisis de la demanda laboral del sector LGBT}

En el presente apartado se presenta como estudio de caso la caracterización de la demanda del sector LGBT en Chapinero a partir de la información suministrada por los dueños y/o administradores de seis establecimientos por medio de la entrevista "Estudio de caracterización de contratantes de mano de obra LGBT en Chapinero", identificando las principales actividades económicas y caracteríscas del empleo de la comunidad de estudio. 
Los bares, discotecas y cafés repesentan 67 por ciento de los establecimientos visitados (Tabla 1). Estas unidades productivas se caracterizan por ser pequeñas empresas que, además de servir como expendio de bebidas alcoholicas, ocio y entretenimiento, ofrecen servicios diferentes en el mismo lugar, como expendio de comidas, karaoke y juegos.

Tabla 1: Actividad económica de los establecimientos LGBT entrevistados

\begin{tabular}{lcr}
\hline Actividad económica & Unidades productivas & Porcentaje \\
\hline Bares, discotecas y cafés & 4 & 67 \\
Video-Cabinas de internet gay & 1 & 17 \\
Spa - Sauna gay & 1 & 17 \\
Total General & 6 & 100 \\
\hline
\end{tabular}

Fuente: elaboración propia a partir de la entrevista de "Caracterización de contratantes de mano de obra LGBT en Chapinero".

Los establecimientos que funcionan como bares, discotecas, cafés y restaurantes representan el ícono para el reconocimiento LGBT en la localidad. Pero existen otras actividades económicas propias de la comunidad que se mantienen al margen del conocimiento y visibilidad de la sociedad, este es el caso de las unidades productivas que funcionan como videos, cabinas de internet gay, spa y saunas. Estos establecimientos, ocultos y que pasan desapercibidos en el paisaje urbano, son preferidos por hombres homosexuales y funcionan epecialmente como puntos de encuentro para el libre desarrollo de la personalidad y sexualidad de las personas que los concurren.

La dinámica económica de la población LGBT está representada, en su gran mayoría, por pequeños y medianos establecimientos, los cuales cuentan con 5 a 15 trabajadores. Para esta investigación, los establecimientos visitados registran un total de 39 empleados (Tabla 2).

Por otro lado, al considerar la composición del mercado laboral LGBT, se evidencia una mayor participación de hombres ( 87 por ciento), de los cuales 62 por ciento son homosexuales, seis por ciento bisexuales y 32 por ciento representa los hombres heterosexuales que trabajan en estos establecimientos. Esto indica cierto margen de discriminación por sexo y orientación sexual en el grupo de entrevistados, ya las mujeres tienen menos participación en estas ocupaciones y existe presencia de personal heterosexual laborando en estos lugares. 
Discriminación y exclusión laboral en la comunidad LGBT: un estudio... /J. JIMÉNEZ-CASTAÑO et al.

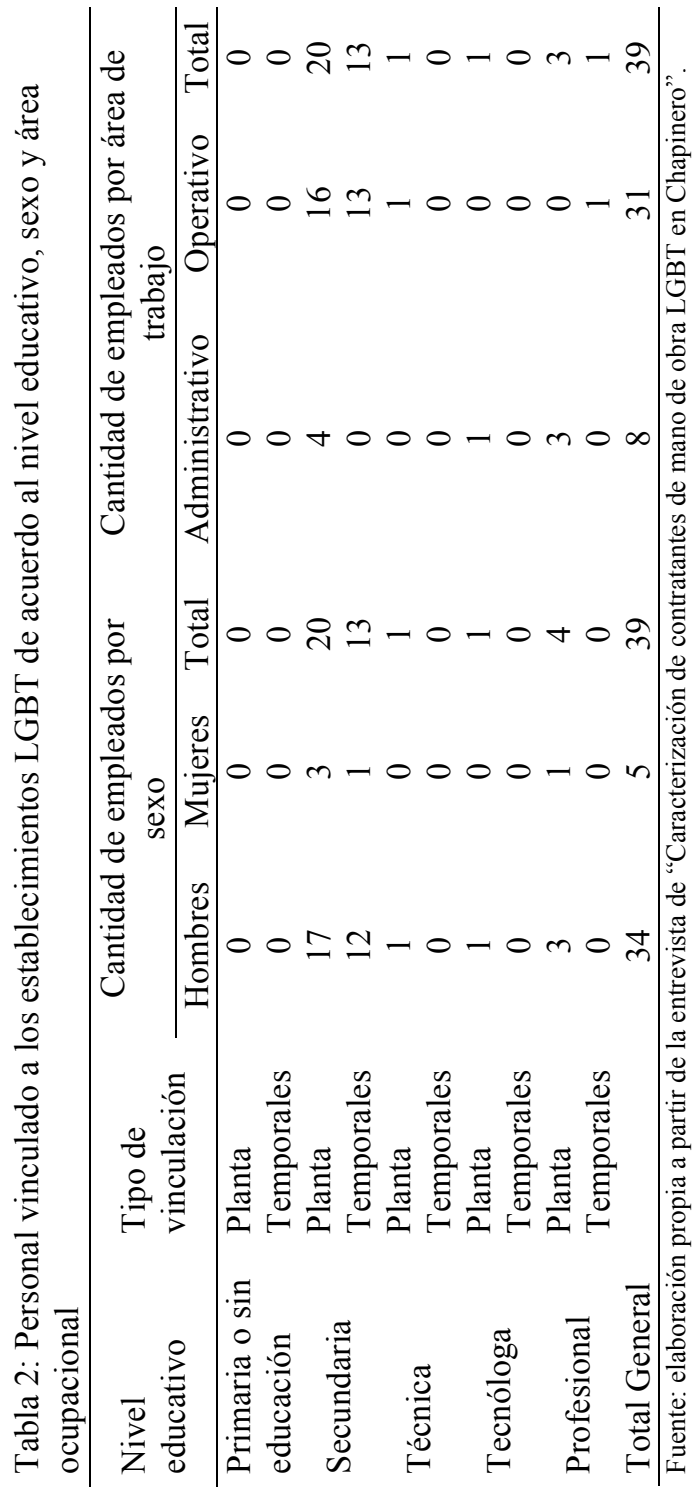


En el trabajo de campo se evidenció que lo anterior se debe posiblemente a que los clientes frecuentes de estos establecimientos son hombres, quienes prefieren ser atendidos por personal masculino, dado que la venta de productos o prestación de algún servicio gira en torno a la buena relación entre empleado y cliente. Para los dueños y empleados este es un método para atraer más clientes y aumentar las ventas.

Otra razón que puede explicar la mínima participación laboral de las mujeres en establecimientos LGBT radica en que la mayoría funcionan en horarios nocturnos, los riesgos y exposiciones al peligro son altos, es frecuente evidenciar casos de peleas, riñas y robos, situaciones que para los empleadores es más fácil lidiar sí vinculan personal masculino. Sin embargo, es común encontrar mujeres trabajando como DJ e incluso ocupando cargos en seguridad del establecimiento, quienes se caracterizaron por ser rudas y tener patrones corporales masculinos, como se logró observar en el trabajo de campo.

Asimismo, se determina que 79 por ciento de los empleos son de carácter operativo y 21 por ciento representa las ocupaciones administrativas. Teniendo en cuenta que estos establecimientos representan pequeñas empresas, es importante mencionar que los dueños y/o administradores, además de encargarse de las ocupaciones administrativas, sirven como apoyo para ejercer las actividades operativas, es usual encontrar a los dueños trabajando como meseros, barman y atendiendo clientes. Por otra parte, 67 por ciento representa la favorabilidad de ocupaciones de planta o permanentes, lo cual no está representado por algún tipo de contrato de trabajo, sino que la permanencia de los trabajadores en estos establecimientos se debe a la confianza e identificación de los trabajadores con el empleador.

Ahora bien, las tareas y ocupaciones en los establecimientos no requieren personal altamente calificado, por tal motivo el bachillerato es el nivel académico que predomina en los trabajadores del sector LGBT; además, los empleadores dan prioridad a los estudiantes universitarios en el momento de vincular a una persona en su establecimiento. Para el caso de las unidades productivas visitadas 85 por ciento de las personas han cursado bachillerato completo, de los cuales la gran mayoría están cursando pregrado, mientras que diez por ciento de trabajadores manifiestan haber alcanzado un título profesional y cinco por ciento un título técnico y tecnólogo.

Bajo estas condiciones, el proceso de selección y vinculación de personal en estos establecimientos es sencillo, se realiza a través de canales directos con entrevistas, aunque muchas veces este proceso de selección es omitido, ya que los trabajadores en su gran mayoría son referidos por 
amigos o conocidos y son vinculados por referencia, sin mayores tramites, sin necesidad de ser entrevistado, pasar por una convocatoria o realizar alguna prueba de práctica. No obstante, los dueños y administradores indicaron tener algunos criterios para seleccionar personal, de los cuales los valores, la actitud para el trabajo, las competencias y habilidades son los de mayor prioridad (Tabla 3).

Tabla 3: Importancia asignada por dueños y administradores a cada criterio para la vinculación de personal /en porcentaje)

\begin{tabular}{lrrr}
\hline \multirow{2}{*}{ Criterios } & \multicolumn{3}{c}{ Nivel de importancia } \\
\cline { 2 - 4 } & Baja & Media & Alta \\
\hline Nivel educativo & 50 & 33 & 17 \\
Competencias & 0 & 17 & 83 \\
Habilidades & 0 & 17 & 83 \\
Valores & 0 & 0 & 100 \\
Experiencia & 17 & 67 & 17 \\
Cercanía & 33 & 67 & 0 \\
Actitud & 0 & 0 & 100 \\
Estrato socioeconómico & 83 & 17 & 0 \\
\hline Fuente: elaboración propia a partir de la entrevista de "Caracterización de contratantes de \\
mano de obra LGBT en Chapinero
\end{tabular}

De la misma forma, la buena presentación personal y adecuada expresión corporal y verbal son los requerimientos más importantes para los dueños o administradores al momento de evaluar a una persona próxima a vincular. Los empleadores indican que el lenguaje corporal, buenos modales y carisma son factores vitales para atraer a los clientes y hacer crecer el negocio.

En este sentido, se observa que existe discriminación laboral por prejuicios y estereotipos en los establecimientos LGBT. Estos mecanismos de discriminación por parte de los empleadores pueden están representados por la asignación de ciertos roles según la identidad sexual, lenguaje corporal y el grado de masculinidad y/o feminidad del trabajador, lo cual impulsa y fortalece la segmentación laboral por género y orientación sexual, determinando así los perfiles ocupacionales de la mano de obra en el mercado de trabajo LGBT.

\section{Análisis de la oferta laboral del sector LGBT}

Con base en la información obtenida de la entrevista de oferta laboral "Estudio de perfiles ocupacionales de la comunidad LGBT en Chapinero", se desarrolla el análisis y estudio de caso de 24 personas pertencientes al sec- 
tor LGBT que trabajan en Chapinero, con el fin de exponer las condiciones sociodemográficas, el perfil y formación laboral de la población de estudio.

En la estructura demográfica del mercado laboral de la población LGBT, imperan los trabajadores hombres (92 por ciento). Como se indicó anteriormente, los empleadores prefieren contratar varones debido a los riesgos de las ocupaciones y la relación con los clientes. Respecto a la orientación sexual, predominan los empleados homosexuales, quienes constituyen 68 por ciento del total del personal masculino, 14 y 18 por ciento representan los hombres bisexuales y trans, respectivamente. En contraste, la baja participación de las mujeres sobre el total de personas entrevistadas es de ocho por ciento.

Con respecto a los rangos de edad, en la mayoria de los establecimientos existe concentración de empleados jovenes entre 18 y 25 años de edad. Los entrevistados afirman que estos trabajos son una fuente de ingresos alternativos para quienes están estudiando, significan el sustento diario, semanal o mensual (depende la periodicidad del pago), representado en gastos de transporte, alimentación, libros y fotocopias académicas, lo cual sirve como apoyo económico en sus hogares. Esta puede ser la razón del por qué los jovenes son los representantes de la mayor parte de la oferta laboral del sector LGBT.

Con respecto a las condiciones de vida determinadas por el lugar de residencia se establece que ningún trabajador se encuentra en situación de pobreza, la clase media-alta está representada por 88 por ciento de los empleados entrevistados y cuatro por ciento recide en zonas de estrato 5 y 6 ; en cambio, ocho por ciento de los entrevistados indicaron vivir en barrios cuya estratificación es 1 y 2 . Ahora bien, la concentración de empleados en Chapinero es de 29 por ciento, esto indica que existe alta relación entre el lugar de la vivienda y el sitio de trabajo. Esta localidad se caracteriza por ser una de las zonas que posee numerosos equipamentos educativos, por estrategia de localización los estudiantes buscan trabajos cerca de sus viviendas y centros educativos, con el fin de minizar los costes de trasporte y alimentación.

Además de ser un sector comercial, en el que se ubican la mayoría de establecimientos LGBT, la UPZ 99 Chapinero se caracteriza por tener sectores de tipo residencial y el uso de este sector para vivienda tambien es representativo de la población de estudio. Para este caso de investigación, 54 por ciento de la mano de obra entevistada (13 individuos) viven solos o con amigos en arriendo, representado especialmente por hombres homosexuales y transgeneristas. Por otro lado, 46 por ciento de los trabajadores 
(11 individuos) indicaron que su hogar está definido por un vinculo familiar, el cual tiene vivienda propia o la están pagando, este es el caso de las mujeres lesbianas, los hombres bisexuales y algunos homosexuales.

La razón del estilo y condición de vivienda puede ser explicado por factores culturales, ya que existe contraposición entre la formación o tradición homofóbica y/o heterosexista de algunos nucleos familiares y la aceptación de la condición sexual no heterosexual de algún miembro del mismo hogar. Por tal motivo, el rechazo por la orientación sexual puede ocasionar, para algunos casos de las personas entrevistadas, que se independicen a temprana edad y decidan subsistir por sí solas sin presiones familiares, o también, son obligadas a abandonar sus hogares, como es el caso de algunos hombres homosexuales y transgeneristas entrevistados para esta investigación. Sin embargo, algunas personas que viven con familiares, manifestaron el deseo de independizarse pero no tienen las capacidades económicas para este fin.

En este sentido, las personas que viven solas indicaron que trabajar en un establecimiento LGBT, especialmente los fines de semana, además de ser un substento para cubrir sus necesidades económicas, también representa un espacio, en el cual no son presionados por su orientación sexual.

Con respecto a los perfiles laborales por formación, niveles de educación y áreas ocupacionales, se encontró que los niveles de escolaridad no son altos, ya que los trabajadores del sector LGBT, en su mayoría, se caracterizan por ser personas jóvenes. Los ciclos de educación intermedia como secundaria y técnica constituyen cerca de 80 por ciento, en su mayoría representado por hombres homosexuales y bisexuales; en contraste, del total de las personas entrevistadas, 17 por ciento han alcanzado un título universitario. Es importante indicar que de la mayoría de las personas con secundaria completa están estudiando carreras universitarias, 38 por ciento de los entrevistados se encuentran cursando pregrado (Tabla 4).

De este modo, del total de mano de obra entrevistada, 92 por ciento se encuentra trabajando (Tabla 5), ocho por ciento restante está representado por dos hombres transgeneristas, quienes no se encontraban ocupados para la fecha de la entrevista, ya que estos individuos se dedican al estilismo, baile y presentación de eventos en establecimientos LGBT, los cuales se caracterizan por ser trabajos precarios e intermitentes.

Asimismo, 50 por ciento de las personas entrevistadas (12 trabajadores) se encuentran estudiando, representado en su mayoria por hombres homosexuales y bisexuales (Tabla 5), dedican su tiempo entre semana para deberes acádemicos y los fines de semana son destinados para laborar en 
los establecimientos LGBT. Por el contrario, los hombres transgeneristas entrevistados tienen poca participación en dentro de los programas de formación académica, ya que indicaron que las ocupaciones que ejercen se caracterizan por tener una remuneración baja, la cual no es suficiente para poder invertir en capital humano, sin ignorar que su construcción e identidad de género puede ser un determinante que los aleja de la posibilidad de alcanzar un nivel educativo alto, a diferencia de los demás sectores de la comunidad.

Tabla 4: Nivel educativo por orientación sexual de los trabajadores entrevistados (en porcentaje)

\begin{tabular}{lrrrrr}
\hline & Lesbiana & Gay & Bisexual & Trans & Total \\
\hline Secundaria completa & 0 & 13 & 4 & 13 & 29 \\
Técnico incompleto & 0 & 4 & 0 & 0 & 4 \\
Técnico completo & 0 & 8 & 0 & 0 & 8 \\
Tecnólogo completo & 0 & 4 & 0 & 4 & 8 \\
Universitario incompleto & 4 & 29 & 4 & 0 & 38 \\
Universitario completo & 4 & 4 & 4 & 0 & 13 \\
Total & 8 & 63 & 13 & 17 & 100 \\
\hline
\end{tabular}

Fuente: elaboración propia a partir de la entrevista de "Caracterización de perfiles ocupacionales de la comunidad LGBT en Chapinero".

Tabla 5: Situación laboral y académica por orientación sexual de las personas entrevistadas

\begin{tabular}{lrrllrrrrrrrr}
\hline & \multicolumn{1}{c}{ Trabajando } & \multicolumn{4}{c}{ Estudiando } \\
\hline & \multicolumn{1}{c}{ Sí } & \multicolumn{1}{c}{ No } & \multicolumn{1}{c}{ Total } & \multicolumn{3}{c}{ No } & \multicolumn{2}{c}{ Total } \\
\hline Lesbiana & 2 & $8 \%$ & 0 & $0 \%$ & 2 & $8 \%$ & 1 & $4 \%$ & 1 & $4 \%$ & 2 & $8 \%$ \\
Gay & 15 & $63 \%$ & 0 & $0 \%$ & 15 & $63 \%$ & 9 & $38 \%$ & 6 & $25 \%$ & 15 & $63 \%$ \\
Bisexual & 3 & $13 \%$ & 0 & $0 \%$ & 3 & $13 \%$ & 2 & $8 \%$ & 1 & $4 \%$ & 3 & $13 \%$ \\
Trans & 2 & $8 \%$ & 2 & $8 \%$ & 4 & $17 \%$ & 0 & $0 \%$ & 4 & $17 \%$ & 4 & $17 \%$ \\
Total & 22 & $92 \%$ & 2 & $8 \%$ & 24 & $100 \%$ & 12 & $50 \%$ & 12 & $50 \%$ & 24 & $100 \%$ \\
\hline
\end{tabular}

Fuente: elaboración propia a partir de la entrevista de "Caracterización de perfiles ocupacionales de la comunidad LGBT en Chapinero".

Ahora bien, al abordar las áreas de formación se evidencia cierta diferencia en los procesos de aprendizaje de los trabajadores, las mujeres lesbianas y hombres homosexuales tienen preferencia por los programas académicos referentes a las Artes y Ciencias del Hábitat (21 por ciento), de los cuales se destacan Arquitectura, Medios audiovisuales, Cine y Televisión, Fotografia, Artes Plásticas y Diseño Gráfico; las Ciencias Sociales, las Ciencias Administrativas y Contables están representadas por 17 por ciento cada una, resaltando Economía, Trabajo Social y Comunicación Social, Contaduria Pública, Administración de Empresas y Administración 
Turistica y Hotelera. Por otro lado, las ingenierías tienen poca participación, representando ocho por ciento, Ingeniería Catastral y Geodesia e Ingeniería Ambiental son las que sobresalen dentro del grupo entrevistado.

Teniendo en cuenta las áreas de formación se puede evidenciar cierto grado de segregación ocupacional, determinada en este caso por factores culturales, es decir, por la identificación que tenga la persona LGBT con la misma comunidad y el reconocimiento o aceptación consigo mismo. De las personas entrevistadas, los estudiantes de carreras vinculadas en las áreas de Artes y Ciencias del Hábitat, Trabajo Social, Comunicación Social y Administración Turistica y Hotelera indican que se reconocen como LGBT, se identifican con la comunidad y no tienen problema de dar a conocer su construcción de género frente a los demás grupos de la sociedad.

En contraste, los estudiantes de Economía, Contaduría Pública, Administración de Empresas e ingenierias indicaron que prefieren ocultar y mimetizar su identidad sexual, ya que suponen que la sociedad tiene el imaginario colectivo de que esta población carece de "seriedad" para ejercer cargos en estas áreas, basandose en prejuicios colectivos, discriminando las capacidades y competencias de cada persona. En este sentido, la segregación ocupacional tambien puede estár determinada por mecanismos de autodiscriminación y autoexclusión. Estos estudiantes son los que fundamentan el trabajo en establecimientos LGBT, no solo como fuente de ingresos, sino como un lugar para desinhibirse y comportarse de acuerdo a su voluntad.

De la misma forma, la organización y estructura de la mano de obra pueden estár determinados por mecanismos de autodiscriminación. Del total del personal entrevistado, el 25 por ciento tienen dos trabajos (seis personas) (Figura 1), quienes laboran en unidades productivas que no están destinadas a prestar servicio a la comunidad LGBT (de lunes a viernes), ellos indicaron que prefieren ocultar su orientación sexual para evitar ser víctimas de posible discriminación por parte de compañeros de trabajo y jefes, en la noche asisten a los centros educativos de formación y los fines de semana se ocupan en establecimientos LGBT.

Por otro lado, 54 por ciento trabaja unicamente en establecimientos LGBT y 21 por ciento restante en establecimientos ajenos a las actividades economicas de la comunidad (Figura 1). 


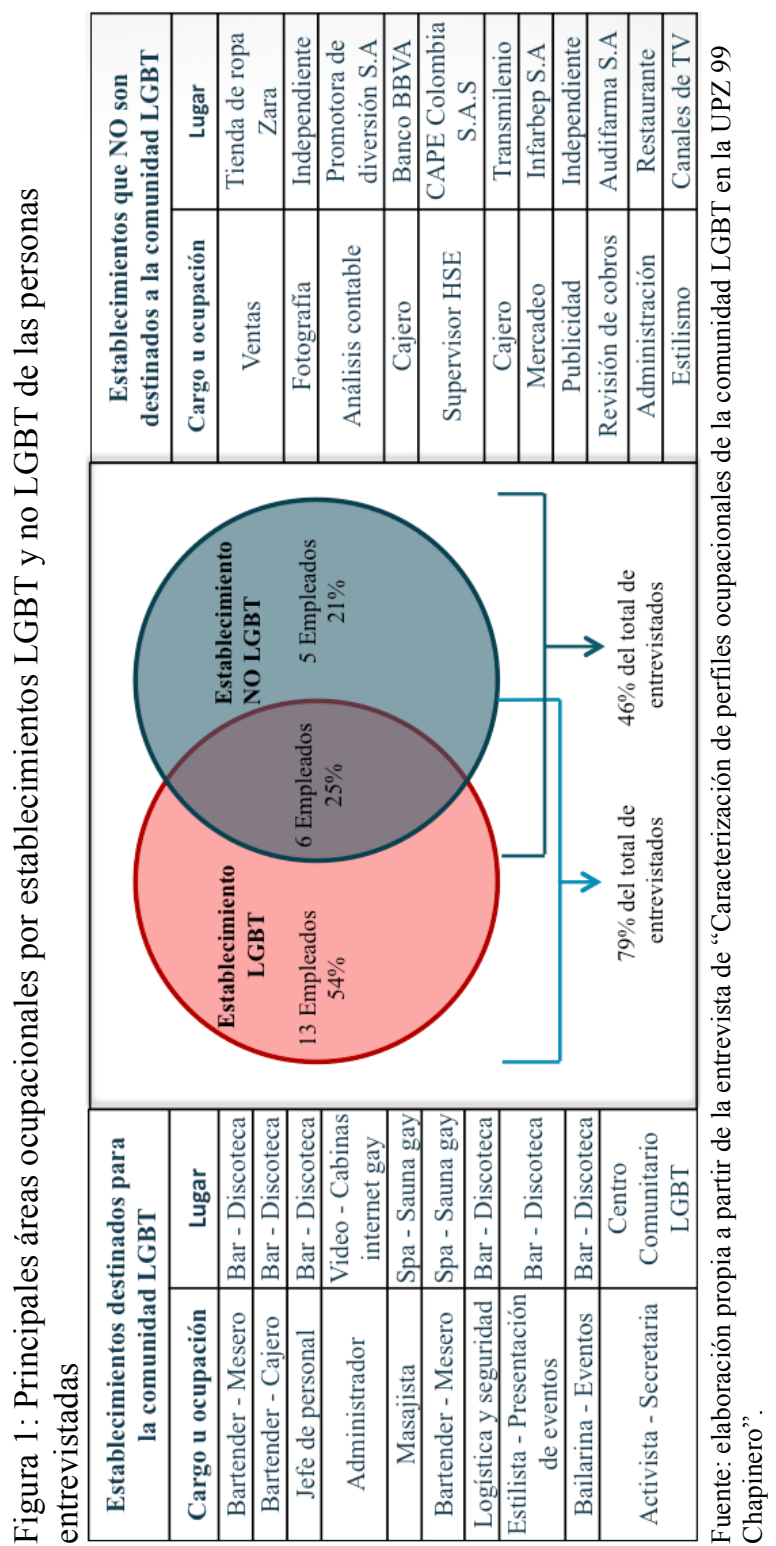


Estos trabajadores, en su mayoria hombres homosexuales y bisexuales vinculados en el mercado laboral formal, quienes se dedican a oficios $\mathrm{u}$ ocupaciones en ventas, contabilidad, mercadeo en empresas privadas y algunos como independientes, manifiestan que prefieren no divulgar su orienteacion sexual en estos espacios laborales, porque imaginan que el resto de la población va a ejercer conductas discriminatorias. Esto posiblemente explica que algunas personas de la comunidad se apropian de supuestos sentimientos de autoestigmatización que terminan en conductas de autoexclusión.

Dentro de los principales oficios ejercidos por las personas entrevistadas se destinguen roles especificos por cada sector de la comunidad LGBT. Priman los cargos operativos, en especial los hombres homosexuales y mujeres lesbianas trabajan como meseros, cajeros y bartender, principalmente en discotecas, bares, cafés y restaurantes. El perfil ocupacional de estas mujeres puede estár determinado por su lenguaje corporal, ya que se observó que si una mujer lesbiana tiene rasgos y expresiones masculinas su cargo se ubica en el área de logística y seguridad.

La participación laboral en el sector LGBT es liderada por los hombres, quienes tambien trabajan en videos, cabinas de internet gay, en spa y saunas, ya sea como administradores, masajistas o bartender. Para el caso de los hombres transgeneristas y transformistas, la segregación ocupacional puede ser más evidente, ya que se dedican al estilismo, baile, presentación de eventos e indicaron no tener otra opción laboral y trabajar en el sector informal por la falta de formación y educación, a excepción de un hombre transgenerista, funcionario activista en un Centro Comunitario LGBT que manifiesta tener un trabajo digno y obtener un salario alto.

En este sentido, partiendo de los perfiles laborales anteriormente descritos se puede identificar los niveles de ingresos de la población LGBT entrevistada. La mayoria de las personas obtienen entre dos y tres SMLMV (Salarios Mínimos Legales Mensuales Vigentes); los hombres homosexuales, además de representar la mayoria del grupo de personas que viven solos o con amigos, en arriendo y tener dos trabajos remunerados, son quienes reciben ingresos más altos, los cuales deben destinar para gastos en vivienda, alimentación, educación y manutención.

Abordando el caso de los hombres trans, se determina que el nivel de ingresos de este sector de la poblacion LGBT es heterogéneo. Para el caso del hombre transformista, quien gana entre 800 mil y un millón de pesos, vive con su familia y no tiene gastos considerables, indica que sus ingresos son suficientes. Con respecto a los tres hombres transgeneristas que 
brindaron información para esta investigación, dos de ellos viven solos, en arriendo y manifiestan que sus ingresos son precarios, ya que para lograr estabilidad en sus ocupaciones como estilistas, bailarines y presentadores de eventos deben invertir una parte considerable de su salario en productos de belleza, estéticos y vestuarios, antes de satisfacer sus necesidades en vivienda digna o alimentación; y el hombre trangenerista que manifiesta ganar más de tres millones de pesos se encuentra en una situación favorable al trabajar bajo contrato a término indefinido en los programas de la Alcaldía Local para el Centro Comunitario LGBT.

Para este caso de estudio, las mujeres lesbianas reciben una remuneración menor que los hombres homosexuales, pero no tienen los mismos gastos, ya que su hogar está compuesto por un núcleo familiar y los padres cabeza de familia son quienes cubren sus necesidades; en este sentido, los salarios de estas mujeres son destinados para gastos o manutención personal y académica.

Teniendo en cuenta la caracterización de los 24 trabajadores del sector LGBT anteriormente descrita, se percibe que la marginación laboral de la mano de obra en establecimientos de dicha comunidad puede ser consecuencia de procesos de autodiscriminación y autoexclusión. De igual manera, este fenómeno agudiza el problema de segregación ocupacional por presencia de posibles imaginarios colectivos para la asignación de ocupaciones para cada sector de la población LGBT o roles sociales estereotipados, lo cual induce a pensar que el mercado laboral para dicha comunidad se encuentra en un marco de desigualdad e influye en la calidad laboral de cada persona.

\section{Calidad laboral de los trabajadores lgbT}

A continuación se derarrolla la descripcion de la calidad laboral de 24 personas, basado en la entrevista semiestructurada sobre "Calidad del trabajo de la población LGBT en Chapinero", determinando las condiciones, exigencias, factores de exposición y carga laboral que constituyen el nivel de bienestar de cada trabajador, a partir de los conceptos que brindan los referentes teoricos sobre formalidad e informalidad laboral de Piore (1969) y calidad de vida desde la perspectiva del enfoque de capacidades de Nussbaum (2007).

\section{Segmentación laboral y seguridad social}

Para determinar la situación contractual de cada trabajador dependiendo el tipo de contrato con que cuentan, es necesario tener presente que algunos 
trabajadores asumen dos ocupaciones, se encuentran laborando tanto en establecimientos LGBT y en establecimientos que no son propios de tal comunidad.

De acuerdo con la Figura 2, tan sólo dos trabajadores de los establecimientos LGBT cuentan con un contrato de trabajo (hombre bisexual masajista en Spa-Sauna gay y hombre tansgenerista activista funcionario del Centro Comunitario LGBT), el resto de empleados (71 por ciento) se caracteríza por laborar en espacios informales (bares, discotecas y cafés, videos y cabinas de internet gay), en donde priman puestos con bajos salarios, condiciones precarias e inestabilidad laboral, es decir, son ocupaciones que se sitúan en el sector secundario que indica Piore (1969).

Figura 2: Tipo de contrato de los trabajadores según establecimiento y orientación sexual

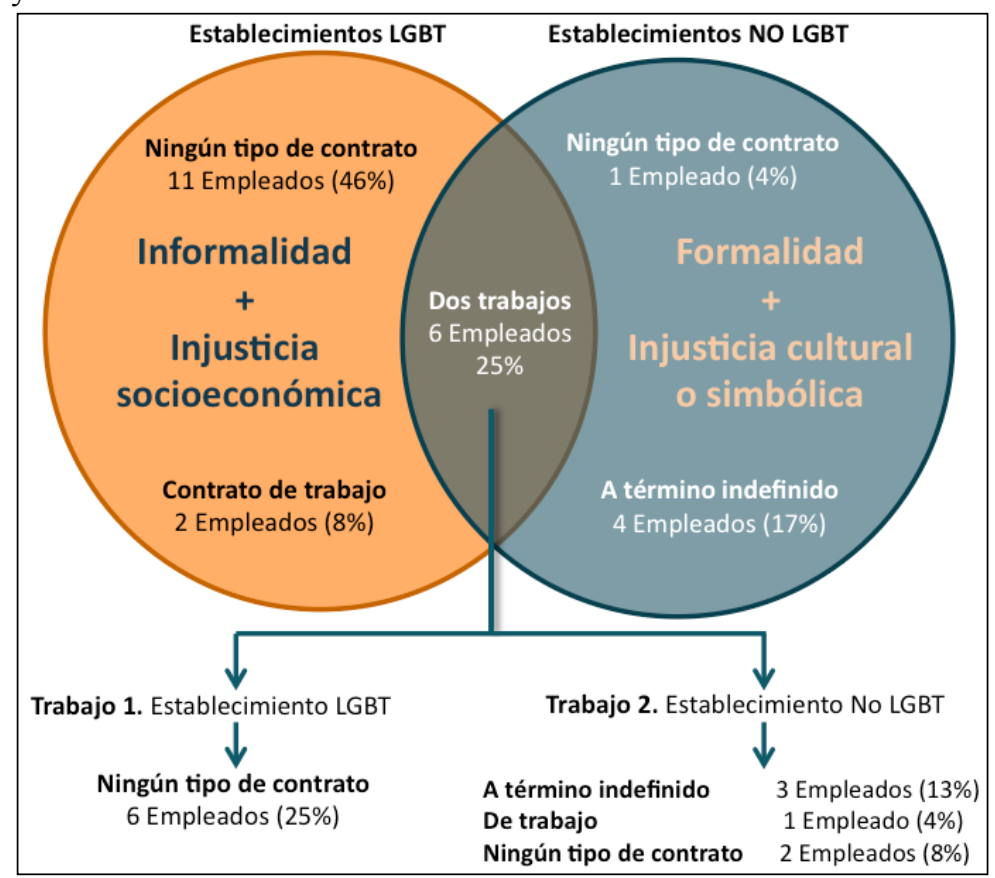

Fuente: elaboración propia a partir de la entrevista sobre "Calidad del trabajo de la comunidad LGBT en Chapinero".

Con respecto a los empleados que no laboran en establecimientos LGBT se determina que están situados en el sector primario de los mercados laborales, ya que 29 por ciento de los trabajadores (siete empleados) cuentan con contratos a término indefinido, cuatro por ciento tiene contrato 
de trabajo (un empleado), en donde existe mayor estabilidad y mejores condiciones de trabajo. En contraste, 13 por ciento de estos empleados no cuenta con algún tipo de contrato, debido a que trabajan como personas independientes en fotografía, publicidad y estilismo.

Teniendo en cuenta la anterior caracterización de los contratos de los trabajadores entrevistados, se evidencia que en los empleos en establecimientos LGBT visitados prevalece la injusticia socioeconómica determinada por la marginación salarial que ocasiona los trabajos mal remunerados e inestables. En cambio, los empleados que tienen dos trabajos y aquellos que trabajan en establecimientos no LGBT se encuentran en una situación favorable al contar con contratos que les garantizan alguna seguridad y estabilidad dentro del sector formal; sin embargo, este grupo de trabajadores puede estár inmerso en la injusticia cultural o simbólica como lo demonina Fraser (1997), ya que no gozan del reconocimiento y no hacen visible su identidad sexual por prácticas representativas de la propia cultura y por mecanismos de autodiscriminación.

De la misma forma, la afiliación a u $\mathrm{n}$ sistema de protección social constituye un marco de seguridad, estabilidad y bienestar para los trabajadores. Los sistemas de salud y pensión deben ser garantizados por el ejercicio de un trabajo digno y formal, en donde se proteja la integridad de cada trabajador. En este sentido, 83 por ciento de los trabajadores entrevistados manifestaron estar afiliados a un sistema de salud que garantice las capacidades de vivir, la salud e integridad física y 46 por ciento indicaron estar cubiertos por un sitema de pensión que asegure el bienestar de cada trabajador a futuro (Tabla 6).

En este punto, el lector se puede preguntar: ¿Por qué la mayoría de los trabajadores estan cubiertos por un sistema de salud si 71 por ciento de los empleos son informales?

Lo anterior se debe a que los ingresos de los trabajadores entrevistados para pagar un sistema de salud no provienen de ellos mismos, ni de su propio trabajo, sino de sus familiares o insitituciones donde estudian (seguro estudiantil). Sabiendo que la mayoría de la población de estudio tiene entre 18 y 25 años de edad, son sus padres quienes cubren el gasto para la protección de la salud y vida de sus familias. En contraste, las 11 personas que trabajan en establecimientos no LGBT y que tienen algún tipo de contrato estan cubiertos por un sistema de salud y cotizan pensión, incluyendo los trabajadores independientes, de los cuales se destaca el caso de un hombre homosexual de 24 años, quien trabaja como publicista independiente y esta cubierto por un sistema de salud y pensión por su padre militar, quien falleció años atrás. 
Discriminación y exclusión laboral en la comunidad LGBT: un estudio... /J. JIMÉNEZ-CASTAÑO et al.

Tabla 6: Protección social de los trabajadores LGBT entrevistados

\begin{tabular}{rccrrrrr}
\hline & & & Lesbiana & Gay & Bisexual & Trans & Total \\
\hline \multirow{6}{*}{ Salud } & Sí & $\mathrm{N}$ & 1 & 12 & 3 & 4 & 20 \\
& tiene & $\%$ & $4 \%$ & $50 \%$ & $13 \%$ & $17 \%$ & $83 \%$ \\
& No & $\mathrm{N}$ & 1 & 3 & 0 & 0 & 4 \\
& tiene & $\%$ & $4 \%$ & $13 \%$ & $0 \%$ & $0 \%$ & $17 \%$ \\
& Total & $\mathrm{N}$ & 2 & 15 & 3 & 4 & 24 \\
& & $\%$ & $8 \%$ & $63 \%$ & $13 \%$ & $17 \%$ & $100 \%$ \\
& Sí & $\mathrm{N}$ & 0 & 8 & 2 & 1 & 11 \\
& tiene & $\%$ & $0 \%$ & $33 \%$ & $8 \%$ & $4 \%$ & $46 \%$ \\
Pensión & No & $\mathrm{N}$ & 2 & 7 & 1 & 3 & 13 \\
& tiene & $\%$ & $8 \%$ & $29 \%$ & $4 \%$ & $13 \%$ & $54 \%$ \\
& Total & $\mathrm{N}$ & 2 & 15 & 3 & 4 & 24 \\
& $\%$ & $8 \%$ & $63 \%$ & $13 \%$ & $17 \%$ & $100 \%$ \\
\hline
\end{tabular}

Fuente: elaboración propia a partir de la entrevista sobre "Calidad del trabajo de la comunidad LGBT en Chapinero".

\section{Remuneraciones}

La calidad laboral también está determinada por el tipo de remuneraciones con las que cuenta cada trabajador, ya que contribuye en las condiciones de trabajo, las jornadas, exigencias, integridad física e intensificación de la mano de obra. Del total de trabajadores entrevistados 25 por ciento manifestó que sus remuneraciones son fijas, representados por hombres homosexuales que trabajan en el sector formal. Por otro lado, una mujer lesbiana, siete hombres homosexuales y bisexuales indican que sus remuneraciones tienen una parte fija y otra variable, mientras que 33 por ciento de los entrevistados, entre ellos una mujer lesbiana, dos hombres gay, un bisexual, tres transegeristas y un transformista, manifiestan que sus remuneraciones son variables en su totalidad.

La variabilidad de los ingresos de las mujeres lesbianas, de los hombres homosexuales y bisexuales depende de la rotación de personal y extensión de la jornada laboral en bares, discotecas y cafés, spa, saunas y cabinas de internet. Para el caso de los hombres transgeneristas la variabilidad de sus remuneraciones depende de la programación de eventos y shows de baile.

\section{Jornadas y horarios de trabajo}

La extención de las jornadas y horarios de trabajo son factores improtantes para evaluar la calidad laboral de las personas, ya que insiden directamente en la integridad física, en el desgaste mental y en los riesgos de los trabajadores. El 29 por ciento de los trabajadores cumplen con jornadas 
de trabajo completas, 13 por ciento con jornadas de trabajo parcial y 58 por ciento declaran trabajar sin limitación de horas. El primer y segundo tipo de jornada laboral corresponde especialmente a los trabajos formales, mientras que las jornadas sin limitación de horas concierne a los trabajos informales en unidades productivas LGBT, donde las jornadas varían dependiendo de la hora de cierre de los establecimientos según la demanda de los clientes.

Con respecto a los horarios de trabajo en los establecimientos LGBT, 75 por ciento de los empleados laboran en horario nocturno, especialmente en discotecas, bares y cafés; el horario del 25 por ciento restante de trabajadores es variable y diurno, correspondiente a oficios en spa-sauna gay, videos y cabinas de internet gay, en donde la rotación de personal es el factor principal que determina los horarios de los trabajadores.

La informacion obtenida muestra que los trabajadores LGBT se encuentran expuestos y vulnerables a sitaciones que ponen en riesgo la salud mental y física, principalmente porque la mayoria trabaja en horarios nocturnos. Asimismo, la extensión y distribución de las jornadas y horarios de trabajo para estos empleados significa la exposición al peligro, especialemente en bares y discotecas de Chapinero, sector en el cual el ocio, el entretenimiento y el consumo de licor van de la mano con el expendio de drogas, la presencia de vandalismo, situaciones de violencia y robos.

\section{Exigencias del trabajo en establecimientos LGBT}

Trabajar apurado, no tener tiempo suficiente para cumplir con sus obligaciones, trabajar bajo presión, intensificación de la capacidades para atender las demandas y cumplir con el volumen de tareas en el trabajo, son factores que determinan el ritmo y calidad de vida laboral de cada trabajador. Para el caso de los trabajadores LGBT entrevistados se determina que 92 por ciento requiere un alto nivel de concentración y atención constante en los establecimientos donde laboran ( 22 empleados), 75 por ciento de los empleados manifestaron trabajar de forma rápida o apurada (18 empleados) y 79 por ciento trabajar bajo mucha presión (19 empleados).

Se observó que el alto nivel te atención y concentracion, trabajar de forma rápida y bajo mucha presión son caracteristicas de los trabajos en unidades productivas LGBT. Los trabajadores ecuestados manifiestan que su trabajo es estresante y agotador. A pesar del estrés y desgaste físico, tan solo 29 por ciento de los trabajadores (siete empleados) indican que su trabajo es monótono, aburrido y repetitivo, mientras que 88 por ciento (21 empleados) manifiestan sentir gusto por su trabajo e indican que es atrac- 
tivo e interesante, independientemente de la insatisfacción que presentan con respecto a las remuneraciones, 50 por ciento de empleados no esta conforme con su salario.

\section{Control sobre el proceso y entorno laboral}

El potencial y el rendimiento de una unidad productiva, en cierta parte, está determinado por la autonomía, resposabilidad, creatividad, iniciativas propias y el control que cada empleado tenga sobre su entorno laboral. En este sentido, un trabajo digno debe caracterizarse por otrogar al empleado la capacidad de participar eficazmente en las decisiones concernientes al trabajo, la libertad de ejercer la relación practica en su proceso y ambiente laboral.

El 83 por ciento de los trabajadores entrevistados declaran que sus ocupaciones requieren de creatividad e iniciativa para introducir nuevas estrategias de venta y servicio al cliente que aumente la productividad de los establecimientos LGBT. Por otro lado, 88 por ciento de los trabajadores indican que deben resolver problemas imprevistos por sí solos, 75 por ciento, debe tomar decisiones dificles y de forma rápida, relacionados a problemas con el público y los clientes y sólo 38 por ciento tiene la libertad de decidir cuando tomar un descanso en su trabajo.

\section{Entorno físico, salud y bienestar}

La calidad laboral esta asociada a la percepción sobre el entorno físico, higiene y seguridad de los trabajadores, 50 por ciento de la población de estudio indica que la luminosidad, temperatura y nivel de ruidos son adecuados en los establecimientos donde trabajan y 71 por ciento (17 empleados) aseguran que las condiciones de higiene y seguridad son buenas. Con respecto a la salud y bienestar de los trabajadores, 88 por ciento manifiesta que su salud se encuentra en buenas condiciones.

A pesar que los trabajadores son personas jóvenes que manifiestan tener buenas condiciones de salud, no tienen en cuenta que estos factores impactan negativamente su calidad de vida. La tranquilidad y bienestar han sido afectadas negativamente por preocupaciones por el miedo a perder el empleo y a la inestabilidad de los trabajos, lo cual hace que las personas se sientan estresadas y agotadas, afectando su estado de ánimo, su salud física y mental. La Tabla 7 muestra el número de trabajadores por orientación sexual que han presentado patologías que representan el desgaste de la salud, la mayoría de trabajadores presenta dolores musculares y cefaleas 
debido al cansancio por las jornadas nocturnas de trabajo, han tenido problemas para dormir y su estado de ánimo es cambiante.

Tabla 7: Condiciones que afectan negativamente la salud física de los trabajadores por orientación sexual

\begin{tabular}{lrrrrr}
\hline & Lesbiana & Gay & Bisexual & Trans & Total \\
\hline Ha tenido preocupaciones por perder & 2 & 10 & 2 & 4 & 18 \\
el empleo & 2 & 13 & 3 & 3 & 21 \\
Se ha sentido cansado y agotado & 2 & 11 & 2 & 4 & 19 \\
Ha estado irritable & 2 & 12 & 2 & 3 & 19 \\
Ha dormido mal & 1 & 11 & 2 & 2 & 16 \\
Ha tenido dolor de cabeza y tensión en & los músculos & & & &
\end{tabular}

Fuente: elaboración propia a partir de la entrevista sobre "Calidad del trabajo de la comunidad LGBT en Chapinero".

\section{Trabajo y tiempo libre}

Las fronteras entre trabajo y la vida cotidiana representan un factor importante para evaluar la calidad de vida, representado en este caso, por el tiempo que dispone cada trabajador para ejercer su ocupacion y el tiempo que dispone para difrutar de actividades recreativas, de ocio y entretenimiento, tiempo con su familia y momentos de descanso y recuperación.

Teniendo en cuenta que los trabajadores del sector LGBT son jovenes estudiantes y que algunos cuentan con dos trabajos, 67 por ciento de los trabajadores entrevistados ( 16 empleados) no tienen tiempo suficiente para pasar tiempo con amigos y entretenimiento, 58 por ciento (14 empleados) no tienen la oportunidad de disfrutar de actividades deportivas, 63 por ciento (15 empleados) indican que las jornadas y horarios de trabajo no les permite dedicarle tiempo a la familia, 75 por ciento (18 empleados) no tienen la oportunidad de salir los fines de semana de paseo o tiempo para vacaciones.

En resumen, los trabajos de las personas entrevistadas en establecimientos LGBT, al parecer no garantizan las libertades, capacidades y condiciones que hacen del trabajo un factor promotor de una buena calidad de vida para poder realizarse humanamente. Las capacidades de razón práctica y afiliación posiblemente son limitadas por los mecanismos de autodiscriminación en espacios formales, marginación salarial y procesos de exclusión.

La salud e integridad física son capacidades que son vulneradas por la inseguridad, los factores de riesgo y el entorno físico de los trabajos LGBT 
en Chapinero, la presión laboral ocasionadas por las largas jornadas y horarios nocturnos de los trabajos informales limita el funcionamiento pleno de las potencialidades, debido al desgaste físico y mental, también ocacionado por la limitación de la autonomía y control sobre el propio entorno.

Por último, para los trabajadores no existen limites ni fronteras entre el trabajo, estudio y la vida, las responsabilidades académicas y laborales no les brinda la oportunidad de dedicar tiempo para el ocio y entretenimiento, para actividades deportivas, salidas vacacionales, ni para pasar tiempo con sus familias.

Ninguna capacidad es garantizada plenamente para los trabajadores LGBT, ni siquiera la que hace referencia a los sentidos, imaginación y pensamiento porque, a pesar que la mayoría de jóvenes se encuentran estudiando carreras profesionales, para algunas personas entevistadas es imposible hacer parte de programas educativos incluyentes por la construcción $\mathrm{y}$ visibilidad de género, este es el caso de los hombres trans.

\section{CONCLUSIONES Y RECOMENDACIONES}

Este estudio resalta la importancia de la interdisciplinariedad para comprender las causas y efectos de los mecanismos discriminadores y segregadores de la población LGBT en espacios laborales. El análisis descriptivo del mercado laboral por medio de un estudio de caso proporciona la aproximación al conocimiento de la realidad social, en este caso la vulnerabilidad de un grupo de personas que hacen parte de población de diversidad sexual.

El perfil empresarial de la comunidad LGBT está caracterizado por establecimientos dedicados al sector servicios, representado por discotecas, bares, cafés, saunas, spa y cabinas de internet gay. En estas unidades productivas, la mano de obra LGBT está constituida por personas jóvenes, estudiantes universitarios, quienes se ocupan principalmente como meseros, bartender y cajeros.

Con el análisis de la demanda laboral del sector LGBT se determinó que estos establecimientos ofrecen trabajos informales y se caracterizan por ser empresas poco competitivas, ya que responden a dinámicas internas de trabajo propias. La explicación de lo anterior radica en que los empleos y salarios no se determinan por las fuerzas del mercado, sino por normas, organizaciones y procedimientos administrativos internos, lo cual está sustentado bajo la teoría de Doeringer y Piore (1970). En este sentido, los modelos de selección de personal y las estructuras de remuneraciones de los establecimientos de estudio, están dominados por la existencia de 
una mayor identificación entre el trabajador con el establecimiento y la comunidad.

Sin embargo, se encontró que existen escenarios de discriminación y exclusión dentro de los establecimientos LGBT para las personas entrevistadas, por parte de empresarios o dueños de las unidades productivas y el mismo público. Lo anterior está representado en la asignación de roles y oficios dentro de estos trabajos, dependiendo de los niveles de masculinidad y feminidad, la visibilidad de la identidad sexual en términos comportamentales y expresiones corporales de los empleados.

En este sentido, se determina que las mujeres lesbianas entrevistadas tienen menor participación laboral dentro del sector LGBT, exceptuando aquellas mujeres cuyo nivel de masculinidad es visible (cabello corto, sin maquillaje, comportamiento rudo, etc.), lo cual las sitúa en oficios de seguridad y logística en discotecas, bares y cafés. Por otro lado, los dueños y administradores contratan hombres homosexuales y bisexuales sujetos a estereotipos y representaciones corporales para cada oficio y ocupación dentro de los establecimientos. Por último, para las personas trans del presente estudio, quienes sufren de discriminación en la construcción de capital humano, la sociedad y el mercado de trabajo no les otorgan otros escenarios laborales que no sea el estilismo, la presentación de shows de eventos y baile de media noche en discotecas y bares.

Por consiguiente, se determina que dentro de los establecimientos LGBT visitados existe segregación ocupacional, dependiendo de la construcción sexual y visibilidad corporal del género, con lo cual se establece que la dinámica económica y de trabajo de la población LGBT puede estár regida por la relación cuerpo-mercado laboral.

Asimismo, se concluye que no solo existe segregación en los establecimientos LGBT entrevistados, sino también hay presencia de este fenoméno por formación profesional y áreas ocupacionales en espacios laborales formales, determinado por el reconocimiento y aceptación consigo mismo e identificación del individuo con la comunidad. Se identificó que las personas que hacen visible su orientacion sexual estudian carreras relacionadas a las Artes, Ciencias del Hábitat, Comunicación Social y Trabajo Social, mientras que las personas que mimetizan su identidad de género estudian carreras enfocadas a las Ciencias Sociales, Contables, Administrativas e Ingienerías, quienes por temor de ser victimas de la presión social, terminan ejerciendo acciones autodiscriminatorias y autoexcluyentes.

En síntesis, los procesos de autodiscrimianción categorizan los trabajos y ocupaciones dentro del sector formal e informal. Los resultados deter- 
minan que las personas que no se identifican con la comunidad LGBT son quienes prefieren ocultar su orientación sexual en espacios laborales formales para evitar ser víctimas de posible lenguaje denigratorio contra ellos. Mientras que aquellas personas que se identifican y reconocen como LGBT están expuestos a permanecer en espacios de trabajos informales y mantenerse en la periferia laboral.

El fenómeno de segregación laboral por procesos de discriminación a la comunidad LGBT, es consecuencia del no reconocimiento como sujetos sociales, representado en la injusticia socieconómica y la injusticia cultural o simbólica, como lo indica Fraser (2004). La marginación salarial, la privación de los bienes necesarios para llevar una vida digna y la dominación cultural posiblemente dependen del reconocimiento que tiene el sujeto consigo mismo, el nivel de masculinidad o feminidad de la persona y sí hace visible o no su identidad sexual.

Con respecto al análisis de las condiciones y calidad de trabajo se encontró que el mercado laboral LGBT no se caracteriza por ofrecer trabajos dignos que contribuyan al mejoramiento de la calidad de vida de las personas entrevistadas y a su realizacion plena bajo la perspectiva de justicia social e igualdad partiendo del enfoque de capacidades, lo cual ratifica que estas personas representan parte de una población que sigue en situación de vulnerabilidad (Anexo 1 y Anexo 2).

La vulnerabilidad de la población en el territorio, muestra que los procesos administrativos locales que buscan proteger y garantizar los derechos de la comunidad LGBT no son efectivos, ni suficientes. La participación e integración social de dicha población es limitada y no presenta la suficiente fuerza para hacer eficientes los objetivos políticos de promover una vida digna. Por lo tanto, los lineamientos normativos, los proyectos y acciones contemplados por los diferentes planes de desarrollo y políticas públicas LGBT a nivel distrital y local, tienen mayor representación simbólica y política, ya que carecen de aplicabilidad y apoyo para eliminar la injusticia social contra la comunidad.

Igualmente, la noción de la localidad de Chapinero como distrito LGBT justifica y legitima la marginación de tal comunidad, la diversidad de género se debe territorializar sin limitar fronteras que determinen que solo se puede ser gay, lesbiana, bisexual o trans en Chapinero. Es necesario que las economías diversas tengan espacio a nivel distrital y sea reconocida la potencialidad de la población por los demás grupos de la sociedad y otorgarles la oportunidad de generar un cambio social sin prejuicios e imaginarios colectivos. Además, el territorio no genera los espacios laborales 
adecuados para que el individuo se realice humanamente dentro de un umbral de justicia social.

En efecto, el fenómeno de segregación laboral por orientación sexual tiene un trasfondo cultural, por lo cual, se recomienda institucionalizar la diversidad en los centros educativos del distrito, estructurar la educación de las nuevas generaciones hacia el reconocimiento de la diferencia, eliminando patrones de discriminación, exclusión e imaginarios culturales que atentan contra el bienestar de ciertos grupos de la sociedad, lo cual indica que la educación hacia la diversidad también debe estar orientada hacia las antiguas generaciones y población de edad avanzada, bajo la necesidad de que comprendan los cambios sociales y culturales que demandan la eliminación de comportamientos heteronormativos, heterosexistas y homofóbicos.

Por último, la reestructuración educativa debe otorgar la capacidad a la población LGBT de empoderamiento y participación en diversas formas de interacción social que promuevan la afiliación y asociación de dicha comunidad.

\section{REFERENCIAS BIBLIOGRÁFICAS}

Alcaldía Mayor de Bogotá, 2004, Recorriendo Chapinero. Diagnóstico físico y socioeconómico de las localidades de Bogotá, Secretaría Distrital de Hacienda. Recuperado el 31/07/2014 en http://impuestos.shd.gov.co/portal/page/portal/portal internet sdh/publicaciones/Est_fis_pub/localidades_est_pub/RECORRIENDŌ_CHAPINERO.pdf

Alcaldía Mayor de Bogotá, 2008a, Cartillas Pedagógicas del POT. Acuerdos para construir ciudad, UPZ 99 Chapinero. Bogotá.

Alcaldía Mayor de Bogotá, 2008b, "Bogotá Positiva: Para vivir mejor", en Plan de Desarrollo Económico, Social, Ambiental y de Obras Públicas para Bogotá D.C., 2008-2012. Secretaría Distrital de planeación. Recuperado el 6708/2014, disponible en http://www.sdp.gov.co/portal/page/portal/PortalSDP/ciudadania/ PlanesDesarrollo/BogotaPositiva/2008_2012_BogotaPositiva_a_Plan_Acuerdo308_2008_aux.pdf

Alcaldía Mayor de Bogotá, 2008c, Por una ciudad de derechos. Lineamientos generales de la política pública para la garantía plena de los derechos de las personas lesbianas, gays, bisexuales y transgeneristas - LGBT - y sobre identidades de género y orientaciones sexuales en el distrito capital. Secretaría Distrital de Planeación Bogotá, Colombia.

Alcaldía Mayor de Bogotá, 2014, Política Pública para la garantía plena de los derechos de las personas lesbianas, gay, bisexuales, transgeneristas e intersexuales- LGBTI - y sobre identidades de género y orientaciones sexuales en el Distrito 
Capital, y se dictan otras disposiciones, Decreto número 062, Secretaría Ditrital de planeación. Recuperado el 9/08/2014, disponible en http://www.sdp.gov.co/ portal/page/portal/PortalSDP/SeguimientoPoliticas/politicasLGBT/QueEs/Decreto_062_2014.pdf

Ardila, R., 2003, "Calidad de vida: una definición integradora”, en Revista Latinoamericana de Psicología, 35(2), 161-164.

Baquero, J., Sarmiento, L. y Guataquí, J., 2000, Un marco analítico de la discriminación laboral. Teorías, Modalidades y Estudios para Colombia. Recuperado el 2/07/2014, Universidad del Rosario: disponible en http://www.urosario.edu.co/ urosario_files/b9/b95818eb-c9d8-42a9-b1d33b398cdd9e65.pdf

Carrasco, I., Castaño, M. y Pardo, I., 2011, "Diferentes desarrollos del mercado de trabajo", en Tendencias y nuevos desarrollos de la teoría económica (858), 98.

Duque, C., 2008, Aproximación teórica al debate por el reconocimiento político, jurídico y social del sector LGTBIQ. Recuperado el 1/08/2014, de Universidad ICESI: disponible en https://www.icesi.edu.co/revistas/index.php/revista_cs/article/view/417

El Universal, 2012, Colombia, tercer país de américa en tener cámara de comercio LGBT. 15 de Septiembre, Recuperado el 19/08/2014, disponible en http:/www. eluniversal.com.co/cartagena/economica/colombia-tercer-pais-de-america-en- tener-camara-de-comercio-lgbt-90942

Fraser, N., 1997, Iustitia interrumpida: reflexiones críticas desde la posición "Postsocialista", Universidad de los Andes. Bogotá, Colombia.

Higua, N., 2012, Análisis del diferencial de la educación superior por género en el mercado laboral de Bogotá durante el periodo 2001-2009. Bogotá, Colombia. Recuperado eel 15/07/2014, de Repositorio institucional UniSalle: disponible en http://repository.lasalle.edu.co/bitstream/10185/18297/1/T10.12\%20H634a.pdf

Junta Administradora Local de Chapinero, 2008, "Bogotá Positiva: Para Vivir Mejor-Chapinero Diversidad Positiva", en Plan de Desarrollo Económico, Social y de Obras Públicas de la Localidad de Chapinero, 2009-2012, Sistema de Documentación e Información Municipal. Recuperado el 12/08/2014, de disponible en http://cdim.esap.edu.co/BancoMedios/Documentos $\% 20 \mathrm{PDF} /$ chapinero $\% 20$ \%20bogotá\%20-\%20pdl\%20-\%202009\%20-\%202011\%20(pág\%2034\%20\%20 $257 \% 20 \mathrm{~kb}) . p d f$

Junta Administradora Local de Chapinero, 2012, "Chapinero Humana para Todos y Todas", en Plan de Desarrollo Económico y Social y de Obras Públicas para la Localidad de Chapinero 2013-2016, recuperado el 16/08/2014, de disponible en http://www.alcaldiabogota.gov.co/sisjur/normas/Norma1.jsp?i=49803

Larrañaga, M., 2000, Análisis teóricos de la desigualdad. Universidad Complutense de Madrid Recuperado el 15/07/2014, disponible en http://pendientedemigracion.ucm.es/info/ec/jec7/pdf/com3-6.pdf

Luna, E., 2011, “Geografía de la diversidad: Chapinero (UPZ99) como distrito LGBT de Bogotá”, en Revista Geográfica de América Centra , 2(47), pp. 1-16. 
Nussbaum, M., 2002, Las mujeres y el desarrollo humano. El enfoque de las capacidades. Barcelona, España.

Nussbaum, M., 2005, Capacidades como titulaciones fundamentales: Sen y la justicia social, Universidad Externado de Colombia. Bogotá, Colombia.

Nussbaum, M., 2007, Las fronteras de la justicia. consideraciones sobre la exclusión, Ediciones Paidós Ibérica, Barcelona, España.

Pérez A., Correa, G. y Castañeda, W., 2013, Raros y oficios. Diversidad sexual y mundo laboral: discriminación y explusión, Escuela Nacional Sindical y Corporación Caribe afirmativo. Medellín Colombia.

Rodríguez, J., 2012, Participación ciudadana de la población LGBT en la localicad de Chapinero del 2007 al 2009, Repositorio Universidad Javeriana. Recuperado el 15/08/2014, disponible en http://repository.javeriana.edu.co/bitstream/10554/1389/1/RodriguezGarciaJohnMarlon2011.pdf

Sen, A., 1996, Capacidades y bienestar, en Nussbaum, M. y Sen, A., La calidad de vida, Fondo de Cultura Económica, México, pp. 54-83.

Yacuzzi, E., 2005, Estudio de caso como metodología de investigación: Metodología, mecanismos causales y validación. Recuperado el 10/09/2014, de Serie documentos de trabajo. Universidad del CEMA: http://www.ucema.edu.ar/publicaciones/download/documentos/296.pdf

\section{RESUMEN CURRICULAR DE LOS AUTORES}

\section{Jorge Luis Jiménez Castaño}

Profesional en Economía, egresado de la Universidad De La Salle, Bogotá, Colombia. Después de finalizar sus estudios universitarios se desempeñó como Analista de Crédito en el Banco Finandina en Bogotá, 2015 a 2016. Actualmente se encuentra realizando estudios de perfeccionamiento del idioma Inglés en Nueva Zelanda. Como primer trabajo de investigación y para optar al título de Economista, realizó un estudio titulado Perfiles Ocupacionales de la Comunidad LGBTI en Chapinero Bogotá Colombia. Dirección electrónica: Jorge.92.jimenez.ec@gmail.com

\section{Marleny Cardona Acevedo}

Postdoctora en Problemas de la Niñez y Juventud en América Latina, Consejo Latinoamericano de Ciencias Sociales. Doctora en Ciencias Sociales. Niñez y Juventud, Universidad de Manizales. Doctora en Ciencias Sociales, Colegio de La Frontera Norte, México. Especialista en Planeación Urbana y Regional, Universidad Nacional de Colombia. Economista, Universidad de Antioquia, Colombia.

Dirección electrónica: marca3.marleny@gmail.com 
Discriminación y exclusión laboral en la comunidad LGBT: un estudio... /J. JIMÉNEZ-CASTAÑO et al.

María del Pilar Sánchez Muñoz

Postulante a Doctora en Desarrollo Sostenible, Universidad de Manizales. Magíster en Economía, Universidad Nacional de Colombia. Economista, Universidad Católica de Colombia. Docente investigadora de la Facultad de Ciencias Económicas y Sociales de la Universidad de La Salle, Bogotá, Colombia. Investigadora del Grupo de Investigación Economía y Desarrollo Humano. Bogotá, Colombia.

Dirección electrónica: mdsanchez@unisalle.edu.co

Artículo recibido el 22 de abril de 2015 y aprobado el 31 de mayo de 2017. 
Anexo 1: Capacidades básicas humanas en función de los perfiles ocupacionales, calidad y condiciones de trabajo de los trabajadores LGBT entrevistados (Nussmaum 2007)

\begin{tabular}{|c|c|c|c|}
\hline Capacidades & Variables & Descripción & Resultados \\
\hline Salud & Salud y bienestar & $\begin{array}{l}\text { Mantener una buena } \\
\text { salud y afiliación a un } \\
\text { régimen de salud. }\end{array}$ & $\begin{array}{l}\text { El } 83 \% \text { de los trabajadores entrevistados } \\
\text { están afiliados a un sistema de salud. Los } \\
\text { ingresos para la afiliación a este régimen } \\
\text { provienen de familiares, no es garantizado } \\
\text { por el trabajo ejercido en establecimientos } \\
\text { LGBT. }\end{array}$ \\
\hline \multirow{2}{*}{$\begin{array}{l}\text { Integridad } \\
\text { Física }\end{array}$} & Seguridad & \multirow{2}{*}{$\begin{array}{l}\text { Jornadas y horarios de } \\
\text { trabajo, exigencias y } \\
\text { condiciones laborales, } \\
\text { entorno físico: } \\
\text { luminosidad y } \\
\text { temperaturas, higiene y } \\
\text { seguridad. }\end{array}$} & \multirow{2}{*}{$\begin{array}{l}\text { El } 75 \% \text { de los empleados laboran en horario } \\
\text { nocturno, el } 58 \% \text { trabajan sin limitación de } \\
\text { horas, dependiendo la hora de cierre de } \\
\text { establecimiento sujeta a demanda del } \\
\text { público. Los trabajadores LGBT se } \\
\text { encuentran en espacios de expendio de } \\
\text { drogas, la presencia de vandalismo, } \\
\text { situaciones de violencia y robos. Durante el } \\
\text { trabajo de campo se observó que el entorno } \\
\text { físico y la seguridad de los establecimientos } \\
\text { no son adecuados, la luminosidad, } \\
\text { temperatura y ruidos de discotecas y bares, } \\
\text { afectan la salud, la integridad física y } \\
\text { mental de las personas a largo plazo. Sin } \\
\text { embargo, los trabajadores manifiestan } \\
\text { laborar en un entorno físico adecuado. }\end{array}$} \\
\hline & $\begin{array}{l}\text { Factores de } \\
\quad \text { riesgo }\end{array}$ & & \\
\hline $\begin{array}{c}\text { Sentidos, } \\
\text { imaginación y } \\
\text { pensamiento }\end{array}$ & $\begin{array}{l}\text { Nivel de } \\
\text { educación }\end{array}$ & $\begin{array}{l}\text { Educación adecuada, } \\
\text { escolaridad. }\end{array}$ & $\begin{array}{l}\text { El } 50 \% \text { de las personas entrevistadas se } \\
\text { encuentran } \\
\text { profesionales. }\end{array}$ \\
\hline Razón práctica & $\begin{array}{l}\text { Libre desarrollo } \\
\text { de su sexualidad } \\
\text { y libertad de } \\
\text { conciencia. }\end{array}$ & \multirow{3}{*}{\begin{tabular}{|} 
Autoreconocimiento, \\
autorrespeto e \\
identificación con la \\
comunidad LGBT, no \\
humillación, no \\
discriminación y no \\
exclusión. Forjar \\
relaciones significativas \\
de mutuo \\
reconocimiento con \\
otros trabajadores y \\
jefes.
\end{tabular}} & \multirow{3}{*}{$\begin{array}{l}80 \% \text { de empleados tienen buena relación, } \\
\text { cuentan con la colaboración y apoyo de } \\
\text { jefes y compañeros de trabajo, el } 88 \% \text { de } \\
\text { trabajadores tienen la percepción de ser } \\
\text { reconocidos en su trabajo y formar parte de } \\
\text { un grupo dada su identidad sexual. Sin } \\
\text { embargo, el } 46 \% \text { que trabajan en espacios } \\
\text { laborales formales no se reconocen como } \\
\text { sujetos LGBT posiblemente ejerciendo } \\
\text { mecanismos de autodiscriminación. }\end{array}$} \\
\hline \multirow{2}{*}{ Afiliación } & $\begin{array}{c}\text { Relaciones } \\
\text { laborales con } \\
\text { jefes, colegas y } \\
\text { público } \\
\end{array}$ & & \\
\hline & Trato digno & & \\
\hline
\end{tabular}

Fuente: elaboración propia con base en el enfoque de capacidades de Martha Nussbaum. 
Anexo 2: Capacidades básicas humanas en función de los perfiles ocupacionales, calidad y condiciones de trabajo de los trabajadores LGBT entrevistados (Nussmaum 2007)

\begin{tabular}{|c|c|c|c|}
\hline Capacidades & Variables & Descripción & Resultados \\
\hline \multirow{5}{*}{$\begin{array}{c}\text { Control sobre el } \\
\text { propio entorno }\end{array}$} & Estrato & Estrato socioeconómico & $\begin{array}{l}\text { Ningún trabajador se encuentra en situación } \\
\text { de pobreza, la clase media-alta está } \\
\text { representada por el } 88 \% \text { de los empleados. }\end{array}$ \\
\hline & Contrato & Tipo de contrato laboral & $\begin{array}{l}\text { El } 75 \% \text { de los empleados que trabajan en } \\
\text { establecimientos LGBT no tienen ningún } \\
\text { tipo de contrato }\end{array}$ \\
\hline & Ingresos & Nivel de ingresos & $\begin{array}{l}\text { La mayoría de las personas obtienen entre } \\
\text { dos y tres SMLMV, teniendo en cuenta que } \\
\text { el } 25 \% \text { de los entrevistados tienen dos } \\
\text { trabajos }\end{array}$ \\
\hline & $\begin{array}{l}\text { Condiciones y } \\
\text { tenencia de } \\
\text { vivienda }\end{array}$ & $\begin{array}{l}\text { Vivienda propia o en } \\
\text { arriendo, vive solo o } \\
\text { acompañado. }\end{array}$ & $\begin{array}{l}\text { El } 54 \% \text { de la mano de obra viven solos o } \\
\text { con amigos en arriendo, el hogar del } 46 \% \\
\text { de los trabajadores está definido por un } \\
\text { vínculo familiar, el cual tiene vivienda } \\
\text { propia o la están pagando. }\end{array}$ \\
\hline & Trabajo digno & $\begin{array}{l}\text { Derecho a un trabajo en } \\
\text { condiciones de igualdad } \\
\text { con los demás, poder } \\
\text { trabajar como un ser } \\
\text { humano, ser reconocido } \\
\text { por sus capacidades, } \\
\text { habilidades y actitudes. } \\
\end{array}$ & $\begin{array}{l}\text { Los empresarios contratan y asignan roles } \\
\text { para cada persona del sector LGBT según } \\
\text { identidad sexual, apariencia física y el } \\
\text { grado de masculinidad y/o feminidad del } \\
\text { trabajador, no tiene en cuenta nivel } \\
\text { educativo y formación profesional. }\end{array}$ \\
\hline $\begin{array}{c}\text { Control sobre el } \\
\text { propio entorno }\end{array}$ & $\begin{array}{l}\text { Autonomía, } \\
\text { responsabilidad y } \\
\text { creatividad }\end{array}$ & $\begin{array}{l}\text { Participar eficazmente } \\
\text { en las decisiones } \\
\text { concernientes al trabajo, } \\
\text { la libertad de ejercer la } \\
\text { relación practica en su } \\
\text { proceso y ambiente } \\
\text { laboral. }\end{array}$ & $\begin{array}{l}\text { El } 92 \% \text { de los trabajadores requiere un alto } \\
\text { nivel de concentración y atención constante, } \\
\text { el } 75 \% \text { manifestó trabajar de forma rápida } \\
0 \text { apurada y el } 79 \% \text { trabajar bajo mucha } \\
\text { presión. El } 88 \% \text { de los trabajadores indican } \\
\text { que deben resolver problemas imprevistos } \\
\text { por sí solos, el } 75 \% \text {, debe tomar decisiones } \\
\text { difíciles y de forma rápida, relacionados a } \\
\text { problemas con el público y los clientes y, } \\
\text { tan sólo el } 38 \% \text { tiene la libertad de decidir } \\
\text { cuándo tomar un descanso en su trabajo. }\end{array}$ \\
\hline Juego & $\begin{array}{l}\text { Recreación y } \\
\text { tiempo libre }\end{array}$ & $\begin{array}{l}\text { Ocio y entretenimiento, } \\
\text { tiempo libre para } \\
\text { actividades deportivas y } \\
\text { recreativas, tiempo libre } \\
\text { con la familia, } \\
\text { vacaciones y salidas. }\end{array}$ & $\begin{array}{l}\text { El } 67 \% \text { de los trabajadores no tienen tiempo } \\
\text { suficiente para pasar tiempo con amigos y } \\
\text { entretenimiento, el } 58 \% \text { no tienen la } \\
\text { oportunidad de disfrutar de actividades } \\
\text { deportivas, el } 63 \% \text { indican que las jornadas } \\
\text { y horarios de trabajo no les permite } \\
\text { dedicarle tiempo a la familia, el } 75 \% \text { no } \\
\text { tienen la oportunidad de salir los fines de } \\
\text { semana de paseo o tiempo para vacaciones. }\end{array}$ \\
\hline
\end{tabular}

